\title{
Guideline for opioid therapy and chronic noncancer pain
}

\author{
Jason W. Busse DC PhD, Samantha Craigie MSc, David N. Juurlink MD PhD, D. Norman Buckley MD, Li Wang PhD, \\ Rachel J. Couban MA MISt, Thomas Agoritsas MD PhD, Elie A. Akl MD PhD, Alonso Carrasco-Labra DDS MSc, \\ Lynn Cooper BES, Chris Cull, Bruno R. da Costa PT PhD, Joseph W. Frank MD MPH, Gus Grant AB LLB MD, \\ Alfonso lorio MD PhD, Navindra Persaud MD MSc, Sol Stern MD, Peter Tugwell MD MSc, Per Olav Vandvik MD PhD, \\ Gordon H. Guyatt MD MSC
}

Cite as: CMAJ 2017 May 8;189:E659-66. doi: 10.1503/cmaj.170363

CMAJ podcasts: author interview at https://soundcloud.com/cmajpodcasts/170363-guide

See related article www.cmaj.ca/lookup/doi/10.1503/cmaj.170431

C hronic noncancer pain includes any painful condition that persists for at least three months and is not associated with malignant disease. ${ }^{1}$ According to seven national surveys conducted between 1994 and 2008, 15\%-19\% of Canadian adults live with chronic noncancer pain. ${ }^{2}$ Chronic noncancer pain interferes with activities of daily living, has a major negative impact on quality of life and physical function, ${ }^{3}$ and is the leading cause of health resource utilization and disability among workingage adults. ${ }^{4,5}$

In North America, clinicians commonly prescribe opioids for acute pain, palliative care (in particular, for patients with cancer) and chronic noncancer pain. Canada has the second highest rate per capita of opioid prescribing in the world when measured using defined daily doses, and the highest when defined using morphine equivalents dispensed, with more than 800 morphine equivalents per capita in $2011 .^{6,7}$

Substantial risks accompany the use of opioids in chronic noncancer pain. In Ontario, admissions to publicly funded treatment programs for opioid-related problems doubled from 2004 to 2013, from 8799 to $18232.8^{8,9}$ Among Ontarians receiving social assistance, 1 of every 550 patients started on chronic opioid therapy died of opioid-related causes at a median of 2.6 years from the first opioid prescription, while 1 in 32 of those receiving $200 \mathrm{mg}$ morphine equivalents daily (MED) or more died of opioid-related causes. ${ }^{10}$ An estimated 2000 Canadians died from opioid-related poisonings in $2015^{11}$ and initial numbers for 2016 are higher, with most deaths attributed to fentanyl. ${ }^{12}$

In 2010, the National Opioid Use Guideline Group offered recommendations for safe and effective use of opioids. ${ }^{13}$ Many of the recommendations were nonspecific and almost all supported the prescribing of opioids; the guideline provided few suggestions about when not to prescribe. ${ }^{11} \mathrm{~A}$ time-series analysis in Ontario, Canada, from 2003 to 2014, found a slight decline in overall opioid

\section{KEY POINTS}

- We recommend optimization of nonopioid pharmacotherapy and nonpharmacologic therapy, rather than a trial of opioids, for patients with chronic noncancer pain.

- Patients with chronic noncancer pain may be offered a trial of opioids only after they have been optimized on nonopioid therapy, including nondrug measures.

- We suggest avoiding opioid therapy for patients with a history of substance use disorder (including alcohol) or active mental illness, and opioid therapy should be avoided in cases of active substance use disorder.

- For patients beginning opioid therapy, we recommend restricting to less than $90 \mathrm{mg}$ morphine equivalents daily (MED) and suggest restricting the maximum prescribed dose to less than 50 mg MED.

- Patients already receiving high-dose opioid therapy $(\geq 90 \mathrm{mg}$ MED) should be encouraged to embark on a gradual dose taper, and multidisciplinary support should be offered where available to those who experience challenges.

prescribing, but no change in rates of fatal opioid overdose and increases in both high-dose opioid prescribing and opioid-related hospital visits. Moreover, $40 \%$ of recipients of long-acting opioids received $>200 \mathrm{mg} \mathrm{MED}$, and $20 \%$ received $>400 \mathrm{mg} \mathrm{MED} .{ }^{14}$

This updated guideline incorporates all new evidence published subsequent to the literature search that was used to inform the 2010 guideline. It adheres to standards for trustworthy guidelines ${ }^{15}$ and aspires to promote evidence-based prescribing of opioids for chronic noncancer pain. The full guideline is available in Appendix 1 (at www.cmaj.ca/lookup/suppl/ doi:10.1503/cmaj.170363/-/DC1) and at http://nationalpaincentre. mcmaster.ca/guidelines.html. 


\section{Scope}

The purpose of this clinical practice guideline is to inform the prescribing of opioids for adults with chronic noncancer pain. The target audience includes those who prescribe opioids or create policy regarding this issue. This guideline does not address the management of acute or subacute pain, care at the end of life or treatment of opioid addiction or opioid use disorder.

\section{Methods}

In developing this guideline, the steering committee followed standards for trustworthy guidelines. ${ }^{15}$ We included innovative approaches for key standards such as patient involvement, panel and committee composition, and competing interest management. We performed systematic reviews and applied the Grading of Recommendations Assessment, Development and Evaluation (GRADE) system to meet standards of evidence assessment and recommendation development. ${ }^{16,17}$ For complete details on our methods, see Appendix 1 and www.magicapp.org/public/guideline/8nyb0E.

Health Canada and a grant from the Canadian Institutes of Health Research provided funding for this guideline.

\section{Guideline development group}

The development of our guideline was supported by four groups: a steering committee, guideline panel, clinical expert committee and patient advisory committee. The four-member steering committee (GHG, JWB, DNJ and DNB) oversaw all aspects of guideline development. Additionally, an evidence synthesis team conducted the systematic reviews and other literature searches.

The guideline panel consisted of 13 clinicians (most with extensive methodological training; one is a medical regulator) and two patient representatives. Most panel members had no financial or intellectual conflicts of interest (see competing interest statements at end of article and at http://nationalpaincentre.mcmaster.ca/guidelines.html). The panel had extensive input into the development and presentation of the recommendations, voted on all recommendations and is ultimately responsible for the recommendations and their presentation.

To ensure that the guideline development was informed by the necessary expertise in management of chronic pain and use of opioids, the steering committee enlisted 13 experienced clinicians to serve on a clinical expert committee. These individuals were not voting panel members and were not present when the recommendations were developed. The clinical expert committee comprised experts with a range of views on the role of opioids in the management of chronic pain, including those who viewed opioids as having an important role and others who viewed the practice of using opioids in this setting with extreme skepticism. This committee informed the selection of guideline recommendation topics, provided clinical practice guidance in areas where evidence was absent or limited, and reviewed the final guideline.

To optimize patient involvement in our guideline, the steering committee included two patient representatives on our guideline panel and created a 16-member patient advisory committee of patients from across Canada with a variety of opinions regarding the use of opioids in the management of chronic pain. Fourteen patients were living with chronic pain and used (or had used) prescription opioids, one had experience with opioid addiction and another represented a family member who had fatally overdosed on prescription opioids. The patient advisory committee approved the outcomes constituting the focus of the systematic reviews that summarized the evidence for our recommendations, and informed our values and preferences statement.

\section{Guideline development}

\section{Research questions}

The evidence synthesis team reviewed the 2010 Canadian Guideline for Safe and Effective use of Opioids for Chronic Non-Cancer Pain, ${ }^{13}$ as well as six other recently published guidelines addressing the use of opioids for chronic noncancer pain, ${ }^{18-22,53}$ and summarized all prior recommendations. The steering committee held a national stakeholder meeting on July 17,2015 , to discuss previous recommendations and identify other relevant topics for recommendations. Attendees included representatives from law enforcement, pharmacy, medical regulation, patient advocacy groups, family medicine, pain medicine, addiction medicine, coroners, nursing, Workers' Compensation Boards, the Canadian Centre on Substance Abuse, the Canadian Agency for Drugs and Technologies in Health (CADTH) and Health Canada.

\section{Systematic reviews}

The evidence synthesis team conducted systematic reviews using standardized forms in an online data abstraction program (DistillerSR, Evidence Partners, Ottawa, Canada; https://systematic -review.ca) to inform our recommendations. The team searched for evidence in AMED, CINAHL, Cochrane Library, Embase, MEDLINE, PsycINFO, and PubMed through October 2016, including randomized trials and observational studies (excluding case reports). The guideline panel and the evidence synthesis team interacted regularly to ensure harmonization of the scope, approach and output of the systematic reviews, and development of the recommendations. The evidence synthesis team created evidence summaries using the GRADE system to provide a clear description of benefits and harms, along with a rating of the certainty of the evidence on an outcome-by-outcome basis (Box 1).

Reviewers from the evidence synthesis team assessed the risk of bias from randomized trials using a modified Cochrane risk of bias instrument, ${ }^{23}$ and from observational studies using criteria from the Users' Guides to the Medical Literature, ${ }^{24}$ including representativeness of the study population, validity of exposure and outcome assessment, loss to follow-up and whether predictive models were optimally adjusted.

\section{Values and preferences}

To complement the research findings and to guide the guideline panel's recommendations, the steering committee developed a values and preferences statement. This statement was informed by a systematic review of the literature of patient values and preferences for opioid therapy, and through discussions with the patient advisory committee (Appendix 2, available at www.cmaj. ca/lookup/suppl/doi:10.1503/cmaj.170363/-/DC1). 


\section{Development of recommendations}

The guideline includes three categories of guidance: recommendations (supported by evidence from randomized controlled trials or observational studies), good practice statements (supported by indirect evidence), and expert guidance (supported by little or no published evidence).

We applied the GRADE system to move from evidence to recommendations..$^{25,26}$ Our guideline panel and clinical expert committee attended an in-person meeting on Jan. 5, 2017, as did representatives from Health Canada. The primary purpose was to discuss issues for which there was no - or very limited - research evidence in order to develop clinical expert guidance. These included restrictions with respect to the quantity of opioids prescribed, use of immediate- versus controlled-release opioids, coprescribing of sedatives, management of opioid-induced sleep apnea or hypogonadism, and strategies for mitigating risk (i.e., treatment agreements, urine drug screening, tamper-resistant formulations, fentanyl patch exchange and coprescribing of naloxone).

\section{Box 1: How to use and understand this guideline}

This guideline provides prescribers and patients with a basis for decisions about using opioids to manage chronic noncancer pain. Prescribers, patients and other stakeholders - particularly regulatory agencies or the courts - should not view the recommendations in this guideline as absolute. No guideline can account for the unique features of patients and their clinical circumstances; this guideline is not meant to replace clinical judgment.

Statements about qualifying remarks and values and preferences are integral parts of the recommendations and are meant to facilitate accurate interpretation of the guideline. These should never be omitted when quoting or translating recommendations from this guideline. Recommendations in this guideline are categorized according to the Grading of Recommendations Assessment, Development and Evaluation (GRADE) system as strong or weak recommendations. ${ }^{15-17}$

Strong recommendations indicate that all or almost all fully informed patients would choose the recommended course of action, and indicate to clinicians that the recommendation is appropriate for all or almost all individuals. Strong recommendations represent candidates for quality of care criteria or performance indicators.

Weak recommendations indicate that the majority of informed patients would choose the suggested course of action, but an appreciable minority would not. With weak recommendations, clinicians should recognize that different choices will be appropriate for individual patients, and they should help patients arrive at a decision consistent with their values and preferences. Weak recommendations should not be used as a basis for standards of practice (other than to mandate shared decision-making).

The guideline also contains best practice statements and clinical expert guidance, which are distinct from recommendations that have been formally categorized using GRADE. Good practice statements represent common-sense practice, are supported by indirect evidence, and are associated with assumed large net benefit. Clinical expert guidance provides direction in areas for which there is either no published evidence or insufficient evidence to justify a formal recommendation. These do not have the force of either recommendations that have been categorized using GRADE or good practice statements.
Members of the guideline panel, along with two Health Canada observers, attended a second in-person meeting on Jan. 6, 2017. Panellists reviewed relevant evidence for each recommendation and used anonymous, online voting software (https://ietd.epistemonikos .org) to select their recommendation: strong in favour, weak in favour, weak against, or strong against. We required endorsement by $80 \%$ of panel members for acceptance of a recommendation.

The guideline panel also endorsed three good practice statements intended to offer actionable guidance for interventions with compelling indirect evidence of large net benefits (www.magicapp. org/goto/guideline/8nyb0E/section/jmA7Mj). ${ }^{27}$ Input from medical regulators (the College of Physicians and Surgeons of Ontario, College of Physicians and Surgeons of British Columbia, College of Physicians \& Surgeons of Nova Scotia and Federation of Medical Regulatory Authorities of Canada) guided our selection of good practice statements.

\section{External review}

We posted the draft guideline recommendations on the National Pain Centre website (http://nationalpaincentre.mcmaster.ca/) for public consultation, from Jan. 30 to Feb. 28, 2017. We encouraged participation by inviting 429 stakeholders by email and announced the opportunity for review through a national press release and on social media.

The steering committee reviewed and summarized more than 500 comments, which it carefully considered when drafting the final guideline. Neither the direction nor strength of any recommendations changed because of feedback; however, the steering committee did make wording changes and added details to clarify areas of concern. Finally, the draft guideline was reviewed by an external review committee for adherence to the "Clinical Practice Guidelines We Can Trust" checklist from the Health and Medicine Division, National Academies of Sciences, Engineering, and Medicine (www.nationalacademies.org/hmd/Reports/2011/Clinical -Practice-Guidelines-We-Can-Trust.aspx).

\section{Guideline format}

We partnered with the Making GRADE the Irresistible Choice (MAGIC) nonprofit initiative to optimize presentation of the guidelines, in digitally structured and multilayered formats available on all devices, and to develop decision aids for clinicians to use in shared decision-making. ${ }^{28}$

\section{Recommendations}

We developed 10 recommendations, 7 of which focus on harm reduction. Box 2 and multilayered formats in MAGICapp (www. magicapp.org/public/guideline/8nyb0E) provide our $10 \mathrm{recom}$ mendations and associated remarks. Here we describe five key recommendations in greater detail.

\section{Maximizing nonopioid treatment}

When considering therapy for patients with chronic noncancer pain, we recommend optimization of nonopioid pharmacotherapy and nonpharmacologic therapy, rather than a trial of opioids (strong recommendation). See www.magicapp.org/goto/ guideline/8nyb0E/rec/LqqP6L for details. 


\section{Rationale}

When added to nonopioids, opioids may achieve, on average, modest improvements in pain and function relative to other pain treatments at the cost of a small but important risk of nonfatal and fatal unintentional overdose, very frequent physical dependence and frequent addiction (Supplementary Tables 3a-e in Appendix 3, avail- able at www.cmaj.ca/lookup/suppl/doi:10.1503/cmaj.170363/-/DC1). As first-line treatment for patients with chronic noncancer pain, several nonopioid therapies may achieve a similar degree of improvement in pain and function (e.g., nonsteroidal anti-inflammatory drugs [NSAIDs], graduated exercise, cognitive behavioural therapy), but without the harms of dependence, addiction and overdose.

\section{Box 2: Summary of recommendations for opioid therapy and chronic noncancer pain*}

Recommendation 1: When considering therapy for patients with chronic noncancer pain, we recommend optimization of nonopioid pharmacotherapy and nonpharmacologic therapy, rather than a trial of opioids (strong recommendation) (www.magicapp.org/goto/guideline/8nyb0E/rec/LqqP6L).

Recommendation 2: For patients with chronic noncancer pain, without current or past substance use disorder and without other active psychiatric disorders, who have persistent problematic pain despite optimized nonopioid therapy, we suggest adding a trial of opioids rather than continued therapy without opioids (weak recommendation) (www.magicapp.org/goto/guideline/8nyb0E/rec/j91boj).

- By a trial of opioids, we mean initiation, titration and monitoring of response, with discontinuation of opioids if important improvement in pain or function is not achieved. The studies that identified substance use disorder as a risk factor for adverse outcomes characterized the conditions as alcohol abuse and dependence, and narcotic abuse and dependence, and sometimes referred to International Classification of Diseases, 9th revision (ICD-9) diagnoses. The mental illnesses identified in studies as risk factors for adverse outcomes were generally anxiety and depression, including ICD-9 definitions, as well as "psychiatric diagnosis," "mood disorder" and post-traumatic stress disorder.

Recommendation 3: For patients with chronic noncancer pain with an active substance use disorder, we recommend against the use of opioids (strong recommendation) (www.magicapp.org/goto/guideline/8nyb0E/rec/jxz7Dn).

- Clinicians should facilitate treatment of the underlying substance use disorders, if not yet addressed. The studies that identified substance use disorder as a risk factor for adverse outcomes characterized the conditions as alcohol abuse and dependence, narcotic abuse and dependence, and sometimes referred to ICD-9 diagnoses.

Recommendation 4: For patients with chronic noncancer pain with an active psychiatric disorder whose nonopioid therapy has been optimized, and who have persistent problematic pain, we suggest stabilizing the psychiatric disorder before a trial of opioids is considered (weak recommendation) (www.magicapp.org/goto/guideline/8nyb0E/rec/jzPK1n).

Recommendation 5: For patients with chronic noncancer pain with a history of substance use disorder, whose nonopioid therapy has been optimized, and who have persistent problematic pain, we suggest continuing nonopioid therapy rather than a trial of opioids (weak recommendation) (www.magicapp.org/goto/guideline/8nyb0E/rec/j79BGn).

- The studies that identified a history of substance use disorder as a risk factor for adverse outcomes characterized the conditions as alcohol abuse and dependence, and narcotic abuse and dependence, and sometimes referred to ICD-9 diagnoses.

Recommendation 6: For patients with chronic noncancer pain who are beginning opioid therapy, we recommend restricting the prescribed dose to less than $90 \mathrm{mg}$ morphine equivalents daily, rather than having no upper limit or a higher limit on dosing (strong recommendation) (www. magicapp.org/goto/guideline/8nyb0E/rec/jmJOVL).

- Some patients may gain important benefit at a dose of more than $90 \mathrm{mg}$ morphine equivalents daily. Referral to a colleague for a second opinion regarding the possibility of increasing the dose to more than $90 \mathrm{mg}$ morphine equivalents daily may therefore be warranted in some individuals.

Recommendation 7: For patients with chronic noncancer pain who are beginning opioid therapy, we suggest restricting the prescribed dose to less than $50 \mathrm{mg}$ morphine equivalents daily (weak recommendation) (www.magicapp.org/goto/guideline/8nyb0E/rec/noAgMj).

- The weak recommendation to restrict the prescribed dose to less than $50 \mathrm{mg}$ morphine equivalents daily acknowledges that there are likely to be some patients who would be ready to accept the increased risks associated with a dose higher than $50 \mathrm{mg}$ in order to potentially achieve improved pain control.

Recommendation 8: For patients with chronic noncancer pain who are currently using opioids, and have persistent problematic pain and/or problematic adverse effects, we suggest rotation to other opioids rather than keeping the opioid the same (weak recommendation) (www. magicapp.org/goto/guideline/8nyb0E/rec/nJM4bL).

- Rotation in such patients may be done in parallel with, and as a way of facilitating, dose reduction.

Recommendation 9: For patients with chronic noncancer pain who are currently using $90 \mathrm{mg}$ morphine equivalents of opioids per day or more, we suggest tapering opioids to the lowest effective dose, potentially including discontinuation, rather than making no change in opioid therapy (weak recommendation) (www.magicapp.org/goto/guideline/8nyb0E/rec/L4BypE).

- Some patients may have a substantial increase in pain or decrease in function that persists for more than one month after a small dose reduction; tapering may be paused or potentially abandoned in such patients.

Recommendation 10: For patients with chronic noncancer pain who are using opioids and experiencing serious challenges in tapering, we recommend a formal multidisciplinary program (strong recommendation) (www.magicapp.org/goto/guideline/8nyb0E/rec/ERX6WL).

- In recognition of the cost of formal multidisciplinary opioid reduction programs and their current limited availability/capacity, an alternative is a coordinated multidisciplinary collaboration that includes several health professionals whom physicians can access according to their availability (possibilities include, but are not limited to, a primary care physician, a nurse, a pharmacist, a physical therapist, a chiropractor, a kinesiologist, an occupational therapist, an addiction medicine specialist, a psychiatrist and a psychologist).

*Available at www.magicapp.org/public/guideline/8nyb0E. 
CADTH has compiled the evidence supporting nonopioid therapies for chronic noncancer pain (www.cadth.ca/evidence-bundles/ opioid-evidence-bundle/browse-category\#alternatives).

\section{Evidence summary}

We found low-quality evidence that opioids may have similar effects on pain relief as NSAIDs, tricyclic antidepressants, or nabilone (a synthetic cannabinoid), and similar improvements in physical function as NSAIDs, anticonvulsants, tricyclic antidepressants or nabilone (Supplementary Tables 3a-e, Appendix 3). High-quality evidence shows that opioids increase the rate of gastrointestinal adverse events compared with NSAIDs, and low-quality evidence shows that they may increase the rate of gastrointestinal adverse events compared with anticonvulsants and tricyclic antidepressants (Supplementary Tables 3a-e, Appendix 3).

\section{Trial of opioids}

For patients with chronic noncancer pain, without current or past substance use disorder and without other active psychiatric disorders, who have persistent problematic pain despite optimized nonopioid therapy, we suggest adding a trial of opioids rather than continued therapy without opioids (weak recommendation). See www.magicapp.org/goto/guideline/8nyb0E/rec/j91boj for details.

By a trial of opioids, we mean initiation, titration and monitoring of response, with discontinuation of opioids if important improvement in pain or function is not achieved. A reasonable trial of therapy should be accomplished within three to six months; opioids provide less pain relief after three months and some patients may continue use to address inter-dose withdrawal symptoms.

The studies that identified substance use disorder as a risk factor for adverse outcomes characterized the conditions as alcohol abuse and dependence, and narcotic abuse and dependence, and sometimes referred to International Classification of Diseases, 9th revision (ICD-9) diagnoses. Moderate-quality evidence did not support an association between smoking status and opioid misuse (adjusted odds ratio [OR] 1.29, 95\% confidence interval [Cl] 0.971.7). ${ }^{29-32}$ The mental illnesses identified in the studies as risk factors for adverse outcomes were most typically anxiety and depression, including use of ICD-9 definitions, as well as "psychiatric diagnosis," "mood disorder" and post-traumatic stress disorder.

\section{Rationale}

When added to nonopioids, opioids achieve, on average, modest improvements in pain and function. Adverse effects include relatively frequent constipation, nausea and vomiting, sedation and addiction, and a small but important risk of unintentional overdose, which can be fatal. The risk of unintentional overdose increases progressively with the daily dose prescribed (Supplementary Table 3f, Appendix 3).

\section{Evidence summary}

We found moderate-quality evidence that opioid add-on therapy versus no opioid add-on therapy has, on average, a modest effect on pain reduction (best estimate of percentage of patients achieving a reduction in pain greater than the minimally important difference is $11.1 \%$ ), and on functional improvement (best estimate for achieving an important improvement in function is $10.0 \%$ ), but also increases the risk of gastrointestinal adverse events, including vomiting, nausea and constipation (5.8\% more gastrointestinal adverse events) (Supplementary Table 3f, Appendix 3).

Chronic opioid therapy (treatment for more than three months) is associated with a $5.5 \%$ risk of addiction and, at very low doses ( $<20 \mathrm{MED} /$ day), a $0.2 \%$ risk of nonfatal overdose and a $0.1 \%$ risk of fatal overdose; the risk of overdose increases at higher doses (Supplementary Table 3f, Appendix 3). In 2013, 4.9\% of Americans admitted to nonmedical use of prescription opioids. ${ }^{33}$ Data from population surveys suggest similar rates among Canadian adults. ${ }^{34}$

\section{Dosing}

For patients with chronic noncancer pain who are beginning opioid therapy, we recommend restricting the prescribed dose to less than $90 \mathrm{mg}$ MED, rather than having no upper limit or a higher limit on dosing (strong recommendation). We suggest restricting the prescribed dose to less than $50 \mathrm{mg}$ MED (weak recommendation). See www.magicapp.org/goto/guideline/8nyb0E/rec/jmJOVL and www. magicapp.org/goto/guideline/8nyb0E/rec/noAgMj for details.

The weak recommendation to restrict the prescribed dose to less than 50 mg MED acknowledges that some patients will be willing to accept the increased risks associated with doses exceeding $50 \mathrm{mg}$ in order to potentially achieve improved pain control. Further, some patients may gain important benefit at a dose of more than $90 \mathrm{mg}$. Referral to a colleague (not necessarily a pain specialist) for a second opinion regarding the possibility of increasing the dose to more than $90 \mathrm{mg}$ MED may therefore be warranted in some individuals.

\section{Rationale}

Observational studies provide moderate-quality evidence of a progressive increase in the likelihood of unintentional nonfatal overdose or death as the prescribed dose of opioids increases. These serious outcomes are very uncommon in patients prescribed less than $50 \mathrm{mg}$ MED, but increase in those prescribed doses of $50 \mathrm{mg}$ to $90 \mathrm{mg}$, and although still uncommon, are further increased in those prescribed doses of more than $90 \mathrm{mg}$ MED.

\section{Evidence summary}

Meta-regression of within-trial comparisons of different doses of opioids found moderate-quality evidence against a dose-response effect for pain relief $(p=0.49)$ or functional recovery $(p=0.22) .{ }^{35-40}$ However, there is likely a dose-dependent increase in the risk of nonfatal opioid overdose: $0.2 \%$ for $<20 \mathrm{mg} \mathrm{MED} /$ day; $0.7 \%$ for 50-99 mg MED/day; and 1.8\% for $\geq 100 \mathrm{mg} \mathrm{MED/day.}{ }^{41}$ Moreover, there is an increased risk of fatal opioid overdose with higher doses: $0.1 \%$ for < $20 \mathrm{mg} \mathrm{MED/day;} 0.14 \%$ for $20-49 \mathrm{mg}$ MED/day; $0.18 \%$ for $50-99 \mathrm{mg}$ MED/day; and $0.23 \%$ for $\geq 100 \mathrm{mg}$ MED/day. ${ }^{10}$

\section{Tapering}

For patients with chronic noncancer pain who are currently using 90 mg MED per day or more, we suggest tapering opioids to the lowest effective dose, potentially including discontinuation, rather than making no change in opioid therapy (weak recommendation). See www.magicapp.org/goto/guideline/8nyb0E/rec/ L4BypE for details. 
Some patients are likely to have a substantial increase in pain or decrease in function that persists for more than one month after a small dose reduction; tapering may be paused and potentially abandoned in such patients.

\section{Rationale}

Reduction in opioid dose may reduce adverse effects, including cognitive impairment and the likelihood of nonfatal or fatal unintentional overdose. If not done gradually, dose reduction may cause increased pain, decreased function or highly aversive symptoms of opioid withdrawal.

\section{Evidence summary}

We found low-quality evidence that tapering may eventually result in a substantial reduction in opioid dose, or cessation of opioids altogether. This may reduce the risk of opioid-related harms, although it is uncertain whether tapering has an effect on pain (Table 1 ).

\section{Implementation}

We have made strong recommendations to optimize nonopioid therapy (including nondrug therapies) before considering a trial of opioids, and to refer patients struggling to reduce their opioid dose for multidisciplinary care. Both recommendations are subject to resource availability: physicians cannot be required to deliver services that are unavailable. Rather, policy-makers should explore opportunities to facilitate access to evidencebased therapies for patients with chronic noncancer pain.

Canadian physicians' awareness of and adherence to the 2010 Canadian guideline recommendations for use of opioids to manage chronic pain have been limited. ${ }^{44}$ We have formally explored barriers to implementation ${ }^{45}$ and used the findings (e.g., excessive length of guidelines) to guide design and format of the current guideline. Clinicians can facilitate shared decision-making using consultation decision aids available through the MAGIC applica-

Table 1: The effect of opioid tapering versus maintaining the dose for adult patients with chronic noncancer pain using $90 \mathrm{mg}$ morphine equivalents of opioids per day or more*

\begin{tabular}{|c|c|c|c|c|}
\hline Outcome follow-up & No. of studies & Absolute effect estimates & Quality of evidence & $\begin{array}{c}\text { Plain language } \\
\text { summary }\end{array}$ \\
\hline $\begin{array}{l}\text { Pain (11-point NRS; } \\
\text { lower is better) } \dagger \\
6-12 \text { mo }\end{array}$ & 2 studies (73 patients) ${ }^{42,43}$ & $\begin{array}{l}\text { In one study, }{ }^{42} \text { pain was reduced on an } \\
11 \text {-point NRS from mean (SD) of } 8.00(0.30) \\
\text { at baseline to } 3.35(0.33) \text { at } 6 \text { mo. } \\
\text { In the other study, } 40 \% \text { of patients } \\
\text { reported less pain, } 28 \% \text { reported no change } \\
\text { and } 33 \% \text { reported more pain after tapering }\end{array}$ & $\begin{array}{l}\text { Very low, due to } \\
\text { serious risk of bias } \ddagger \\
\text { and serious } \\
\text { imprecision§ }\end{array}$ & $\begin{array}{l}\text { We are uncertain } \\
\text { about the effect } \\
\text { of tapering on } \\
\text { pain }\end{array}$ \\
\hline $\begin{array}{l}\text { Success of tapering } \\
6-12 \text { mo }\end{array}$ & 2 studies (73 patients) $)^{42,43}$ & $\begin{array}{l}\text { In one study, }{ }^{42} 100 \% \text { of patients } \\
\text { successfully tapered opioids. } \\
\left.\text { In the other study, },^{43} 47 \text { of } 50 \text { ( } 94 \%\right) \text { of } \\
\text { patients successfully tapered opioids }\end{array}$ & $\begin{array}{l}\text { Low, due to serious } \\
\text { indirectness } ₫ \text { and } \\
\text { serious imprecision§ }\end{array}$ & $\begin{array}{l}\text { Success of } \\
\text { tapering may be } \\
\text { high in this patient } \\
\text { population }\end{array}$ \\
\hline \multicolumn{5}{|c|}{$\begin{array}{l}\text { Note: NRS = Numeric Pain Rating Scale, SD = standard deviation. } \\
\text { *Available at www.magicapp.org/SoF9. } \\
\text { †Minimally important difference for pain on an 11-point NRS is a reduction of } 2 \text { points. } \\
\text { †Neither study enrolled a comparison group. } \\
\S \text { Small number of patients. } \\
\text { IThese } 2 \text { studies defined "success of tapering" differently. Baron and McDonald } \\
\text { prescription opioids if the patient or physician felt that the patient was not getting benefit from high doses of opioids. No patient was referred for diversion, overuse, abuse or } \\
\text { addiction to opioids. The goal of the program was to taper patients completely off opioids. Harden and colleagues }{ }^{43} \text { included individuals drawn from a list of patients initiated on an } \\
\text { opioid taper at a US Veterans Affairs medical centre. A taper was considered successful if the patient's dose at } 12 \text { months was less than the baseline dose. }\end{array}$} \\
\hline
\end{tabular}

Table 2: Conversion ratios for opioids

\begin{tabular}{|c|c|c|c|c|}
\hline Opioids* & $\begin{array}{l}\text { To convert to oral } \\
\text { morphine equivalent, } \\
\text { multiply by: }\end{array}$ & $\begin{array}{l}\text { To convert from oral } \\
\text { morphine, multiply by: }\end{array}$ & $\begin{array}{l}50 \mathrm{mg} \text { morphine } \\
\text { equivalent dose, } \mathrm{mg} / \mathrm{d}\end{array}$ & $\begin{array}{l}90 \mathrm{mg} \text { morphine } \\
\text { equivalent dose, } \mathrm{mg} / \mathrm{d}\end{array}$ \\
\hline Codeine & $0.1-0.2$ & 6.67 & 334 & 600 \\
\hline Hydromorphone & 5.0 & 0.2 & 10 & 18 \\
\hline Morphine & 1.0 & 1.0 & 50 & 90 \\
\hline Oxycodone & 1.5 & 0.667 & 33 & 60 \\
\hline Tapentadol & $0.3-0.4$ & 3.33 & 160 & 300 \\
\hline Tramadol & $0.1-0.2$ & 6.0 & 300 & $540 \dagger$ \\
\hline
\end{tabular}


tion. ${ }^{46}$ We are seeking funds to support the development, delivery and measurement of a national knowledge translation strategy.

The National Pain Centre (http://nationalpaincentre.mcmaster. $\mathrm{ca} /$ ) aims to provide an ongoing review of new evidence by dynamically updating recommendations as needed, yielding a "living guideline." ${ }^{46}$ Having all the content digitally structured and published in MAGICapp facilitates dynamic updating from a technical perspective; however, updating of guidelines requires resources for which the centre is seeking funds. If we are unable to implement the dynamic updating process, we plan to update this guideline (at minimum) within five years of publication (estimated 2022).

\section{Other guidelines}

Several guidelines for prescribing of opioids for chronic pain have been published in the last five years (Appendix 4, available at www. cmaj.ca/lookup/suppl/doi:10.1503/cmaj.170363/-/DC1); however, only the 2016 United States Centers for Disease Control and Prevention (CDC) guideline ${ }^{47}$ has been endorsed by selected provincial colleges of physicians and surgeons ${ }^{48,49}$ in Canada. Our recommendations regarding dose escalation for patients initiating opioid therapy are consistent with the CDC guideline. Limitations of the CDC guideline include the heavy involvement of experts critical of opioid use for chronic noncancer pain, limited involvement of patients, excessive restrictions on the selection of evidence, suboptimal application of the GRADE rating system, excessive use of strong recommendations in the face of low-quality evidence and vagueness in some recommendations..$^{50}$ The current guideline addresses these limitations.

\section{Gaps in knowledge}

Clinical trials of opioids for chronic noncancer pain failed to follow patients for more than one year, enrolled limited patient populations and did not provide a comprehensive assessment of outcomes. None of the instruments designed for screening patients for high risk of adverse outcomes with opiate use have been shown to predict patients unsuitable for opioid therapy, ${ }^{51}$ and no risk mitigation strategy has convincingly shown reduced harm for patients prescribed opioid therapy. Research addressing these issues would be valuable.

\section{Conclusion}

The limited evidence base for opioid therapy for chronic noncancer pain supports offering a trial of opioids to selected patients with chronic noncancer pain who have not found sufficient relief with optimized nonopioid therapy (see Table 2 for opioid conversions). ${ }^{52}$ The harms associated with opioid therapy are substantial; indeed, 7 of our 10 recommendations focus on harm prevention. Although the evidence supports dose limits for patients beginning opioid therapy, those currently receiving high-dose opioid therapy constitute a distinct population, and tapering efforts should be individualized and should consider patients' values and preferences.

\section{References}

1. Merskey H, Bogduk N; Task Force on Taxonomy of the International Association for the Study of Pain. Classification of chronic pain, second edition (revised). Seattle (WA): International Association for the Study of Pain; 1994.
2. Reitsma ML, Tranmer JE, Buchanan DM, et al. The prevalence of chronic pain and pain-related interference in the Canadian population from 1994 to 2008. Chronic Dis Inj Can 2011;31:157-64.

3. Hogan ME, Taddio A, Katz J, et al. Health utilities in people with chronic pain using a population-level survey and linked health care administrative data. Pain 2017;158:408-16.

4. Loeser JD. Economic implications of pain management. Acta Anaesthesiol Scand 1999;43:957-9.

5. Lynch ME. The need for a Canadian pain strategy. Pain Res Manag 2011;16:77-80.

6. International Narcotics Control Board. Narcotic drugs: estimated world requirements for 2004, statistics for 2002. New York: United Nations; 2004.

7. International Narcotics Control Board. Availability of internationally controlled drugs: ensuring adequate access for medical and scientific purposes. New York: United Nations; 2016.

8. Murphy Y, Goldner EM, Fischer B. Prescription opioid use, harms and interventions in Canada: a review update of new developments and findings since 2010. Pain Physician 2015;18:E605-14.

9. Fischer B, Nakamura N, Rush B, et al. Changes in and characteristics of admissions to treatment related to problematic prescription opioid use in Ontario, 2004-2009. Drug Alcohol Depend 2010;109:257-60.

10. Kaplovitch E, Gomes T, Camacho X, et al. Sex differences in dose escalation and overdose death during chronic opioid therapy: a population-based cohort study. PLoS One 2015;10:e0134550.

11. Fischer B, Rehm J, Tyndall M. Effective Canadian policy to reduce harms from prescription opioids: learning from past failures. CMAJ 2016;188:1240-4.

12. A province-by-province look at opioid-overdose stats, including fentanyl. Global News 2016 Nov. 17. Available: http://globalnews.ca/news/3072316/a-province -by-province-look-at-opioid-overdose-stats-including-fentanyl/ (accessed 2017 Apr. 7).

13. Canadian guideline for safe and effective use of opioids for chronic non-cancer pain Canada. Canada: National Opioid Use Guideline Group (NOUGG); 2010.

14. Fernandes K, Martins D, Juurlink D, et al. High-dose opioid prescribing and opioidrelated hospitalization: a population-based study. PLoS One 2016;11:e0167479.

15. Laine C, Taichman DB, Mulrow C. Trustworthy clinical guidelines. Ann Intern Med 2011;154:774-5.

16. Guyatt GH, Oxman AD, Kunz R, et al. Going from evidence to recommendations. BMJ 2008;336:1049-51.

17. Guyatt GH, Oxman AD, Vist GE, et al. GRADE: an emerging consensus on rating quality of evidence and strength of recommendations. BMJ 2008;336:924-6.

18. Hegmann KT, Weiss MS, Bowden K, et al. ACOEM practice guidelines: opioids for treatment of acute, subacute, chronic, and postoperative pain. J Occup Environ Med 2014;56:e143-59.

19. Manchikanti L, Abdi S, Atluri S, et al. American Society of Interventional Pain Physicians (ASIPP) guidelines for responsible opioid prescribing in chronic non-cancer pain: Part 2-guidance. Pain Physician 2012;15(Suppl):S67-116.

20. Interagency guideline on opioid dosing for chronic noncancer pain: an education aid to improve care and safety with opioid therapy. Olympia (WA): Washington State Agency Medical Directors Group; 2010. Available: www.agencymeddirectors.wa. gov/Files/OpioidGdline.pdf (accessed 2017 Mar. 9).

21. New York City Department of Health and Mental Hygiene. Preventing misuse of prescription opioid drugs. City Health Information 2011;30:23-30.

22. $V A / D O D$ clinical practice guideline: management of opioid therapy for chronic pain. Washington (DC): Department of Veterans Affairs/Department of Defense; 2010. Available: www.va.gov/painmanagement/docs/cpg_opioidtherapy_fulltext.pdf (accessed 2017 Mar. 9).

23. Akl EA, Sun X, Busse JW, et al. Specific instructions for estimating unclearly reported blinding status in randomized trials were reliable and valid. J Clin Epidemiol 2012;65:262-7.

24. Randolph AG, Cook DJ, Guyatt G. Prognosis. In: Guyatt G, Rennie D, Meade MO, et al., editors. Users' guides to the medical literature: a manual for evidence-based clinical practice. 3rd ed. New York: American Medical Association; 2015:421-9.

25. Andrews J, Guyatt G, Oxman AD, et al. GRADE guidelines: 14. Going from evidence to recommendations: the significance and presentation of recommendations. J Clin Epidemiol 2013;66:719-25.

26. Andrews JC, Schunemann HJ, Oxman AD, et al. GRADE guidelines: 15. Going from evidence to recommendation-determinants of a recommendation's direction and strength. J Clin Epidemiol 2013;66:726-35.

27. Guyatt GH, Alonso-Coello P, Schunemann HJ, et al. Guideline panels should seldom make good practice statements: guidance from the GRADE Working Group. J Clin Epidemiol 2016;80:3-7.

28. Vandvik PO, Brandt L, Alonso-Coello P, et al. Creating clinical practice guidelines we can trust, use, and share: a new era is imminent. Chest 2013;144:381-9.

29. Hylan TR, Von Korff M, Saunders K, et al. Automated prediction of risk for problem opioid use in a primary care setting. J Pain 2015;16:380-7.

30. Banta-Green CJ, Merrill JO, Doyle SR, et al. Opioid use behaviors, mental 
health and pain - development of a typology of chronic pain patients. Drug Alcohol Depend 2009;104:34-42.

31. Colburn JL, Jasinski DR, Rastegar DA. Long-term opioid therapy, aberrant behaviors, and substance misuse: comparison of patients treated by resident and attending physicians in a general medical clinic. J Opioid Manag 2012;8:153-60.

32. Ives TJ, Chelminski PR, Hammett-Stabler CA, et al. Predictors of opioid misuse in patients with chronic pain: a prospective cohort study. BMC Health Serv Res 2006;6:46.

33. Han B, Compton WM, Jones CM, et al. Nonmedical prescription opioid use and use disorders among adults aged 18 through 64 years in the United States, 2003-2013. JAMA 2015;314:1468-78.

34. Fischer B, Argento E. Prescription opioid related misuse, harms, diversion and interventions in Canada: a review. Pain Physician 2012;15(Suppl 3):ES191-203.

35. Dapoigny M, Abitbol JL, Fraitag B. Efficacy of peripheral kappa agonist fedotozine versus placebo in treatment of irritable bowel syndrome. A multicenter dose-response study. Dig Dis Sci 1995;40:2244-9.

36. Gana TJ, Pascual ML, Fleming RR, et al. Extended-release tramadol in the treatment of osteoarthritis: a multicenter, randomized, double-blind, placebocontrolled clinical trial. Curr Med Res Opin 2006;22:1391-401.

37. Vorsanger GJ, Xiang J, Gana TJ, et al. Extended-release tramadol (tramadol ER) in the treatment of chronic low back pain. J Opioid Manag 2008;4:87-97.

38. DeLemos BP, Xiang J, Benson C, et al. Tramadol hydrochloride extendedrelease once-daily in the treatment of osteoarthritis of the knee and/or hip: a double-blind, randomized, dose-ranging trial. Am J Ther 2011;18:216-26

39. Rauck R, Rapoport R, Thipphawong J. Results of a double-blind, placebocontrolled, fixed-dose assessment of once-daily OROS(R) hydromorphone ER in patients with moderate to severe pain associated with chronic osteoarthritis. Pain Pract 2013;13:18-29.

40. Mangel AW, Bornstein JD, Hamm LR, et al. Clinical trial: asimadoline in the treatment of patients with irritable bowel syndrome. Aliment Pharmacol Ther 2008;28:239-49.

41. Dunn KM, Saunders KW, Rutter CM, et al. Opioid prescriptions for chronic pain and overdose: a cohort study. Ann Intern Med 2010;152:85-92.

42. Baron MJ, McDonald PW. Significant pain reduction in chronic pain patients after detoxification from high-dose opioids. J Opioid Manag 2006;2:277-82.
43. Harden $\mathrm{P}$, Ahmed S, Ang K, et al. Clinical implications of tapering chronic opioids in a veteran population. Pain Med 2015;16:1975-81

44. Allen MJ, Asbridge MM, Macdougall PC, et al. Self-reported practices in opioid management of chronic noncancer pain: a survey of Canadian family physicians. Pain Res Manag 2013;18:177-84.

45. Chang Y, Zhu KL, Florez ID, et al. Attitudes toward the Canadian guideline for safe and effective use of opioids for chronic non-cancer pain: a qualitative study. J Opioid Manag 2016;12:377-87.

46. Agoritsas $T$, Heen AF, Brandt L, et al. Decision aids that really promote shared decision making: the pace quickens. BMJ 2015;350:g7624.

47. Dowell D, Haegerich TM, Chou R. CDC guideline for prescribing opioids for chronic pain - United States, 2016. MMWR Recomm Rep 2016;65:1-49.

48. College Board adopts new professional standard on safe prescribing to address public health emergency related to opioid overdoses [media release]. Vancouver: College of Physicians and Surgeons of British Columbia; 2016 June 1. Available: www.cpsbc.ca/files/pdf/2016-06-01-Board-Adopts-New-Standard-on-Safe-Prescribing.pdf (accessed 2017 Feb. 11).

49. College endorses the US Centers for Disease Control and Prevention's guidelines for prescribing opioids for chronic pain [media release]. Halifax (NS): College of Physicians \& Surgeons of Nova Scotia; 2016. Available: www.cpsns.ns. ca/News/Press-Releases/Details/Articleld/266/College-Endorses-CDC-Guidelines -for-Prescribing-Opioids-for-Chronic-Pain (accessed 2017 Mar. 11).

50. Busse JW, Juurlink D, Guyatt GH. Addressing the limitations of the CDC guideline for prescribing opioids for chronic noncancer pain. CMAJ 2016;188:1210-1.

51. Kaye AD, Jones MR, Kaye AM, et al. Prescription opioid abuse in chronic pain: an updated review of opioid abuse predictors and strategies to curb opioid abuse (part 2). Pain Physician 2017;20(2S):S111-S133.

52. Nielsen S, Degenhardt L, Hoban B, Gisev N. A synthesis of oral morphine equivalents (OME) for opioid utilisation studies. Pharmacoepidemiol Drug Saf. 2016;25(6):733-7. Available: http://onlinelibrary.wiley.com/doi/10.1002/pds.3945/full.

53. Rolfs RT, Johnson E, Williams NJ, Sundwall DN. Utah clinical guidelines on prescribing opioids for treatment of pain. J Pain Palliat Care Pharmacother. 2010;24(3):219-35.
Competing interests: D. Norm Buckley and Jason Busse report grants from Health Canada during the conduct of the study. Jason Busse received grants from the Canadian Institutes of Health Research (CIHR) during the conduct of the study. D. Norm Buckley reports grants from Purdue Pharma and Janssen Inc. outside the submitted work. Chris Cull received personal fees from Indivior. David Juurlink reports grants from $\mathrm{CIHR}$ and from the Ontario Ministry of Health and Long-Term Care, and personal fees outside the submitted work. Sol Stern was a member of advisory boards for Astra Zeneca, Bristol-Myers Squibb and Johnson and Johnson; received fees for expert opinions from the Canadian Medical Protective Association; received consulting fees from mdBriefCase.com, Ethypharm and Sea Courses; and received honoraria for Continuing Medical Education presentations from Purdue Pharma and Paladin. No other competing interests were declared.

This article has been peer reviewed.

Affiliations: The Michael G. DeGroote Institute for Pain Research and Care (Busse, Buckley, Couban, Craigie and Wang), Department of Anesthesia (Busse and Buckley), Department of Health Research Methods, Evidence, and Impact (Busse, Carrasco-Labra, lorio and Guyatt), McMaster University, Hamilton, Ont.; University Hospitals of Geneva (Agoritsas), Geneva, Switzerland; American University of Beirut (Akl), Beirut, Lebanon; Canadian Pain Coalition (Cooper), Oshawa, Ont.; Department of Oral and Maxillofacial Surgery, Faculty of Dentistry (Carrasco-Labra), University of Chile, Santiago, Chile; Inspire by Example, Canada (Cull); Institute of Primary Health Care (da Costa), University of Bern, Bern, Switzerland;
VA Eastern Colorado Health Care System (Frank), Denver, Colo. and University of Colorado School of Medicine (Frank), Aurora, Colo.; College of Physicians and Surgeons of Nova Scotia (Grant), Halifax, NS; Departments of Medicine and Pediatrics (Juurlink), University of Toronto, Toronto, Ont.; Li Ka Shing Knowledge Institute (Persaud), St. Michael's Hospital, Toronto, Ont.; Argus Medical Centre (Stern), Oakville, Ont.; Department of Medicine (Tugwell), University of Ottawa, Ottawa, Ont.; Innlandet Hospital Trust-Division Gjøvik (Vandvik), Norway

Contributors: All of the authors contributed substantially to the interpretation of the findings and to writing the article. All of the authors gave final approval of the version to be published and agreed to act as guarantors of the work. Participation in the clinical expert committee or patient advisory committee in no way constitutes endorsement of guideline recommendations.

Funding: This guideline was an investigatorinitiated study, supported by grants from the Canadian Institutes of Health Research and Health Canada. Health Canada personnel provided non-binding feedback during the preparation of the guideline. The funders had no other role in the design or conduct of the study; collection, analysis and interpretation of the data; or preparation, review or approval of the guideline. Final decisions regarding the protocol and issues that arose during the guideline development process were solely the responsibility of the guideline steering committee.

Disclaimer: Nav Persaud is an associate editor for CMAJ and was not involved in the editorial decision-making process for this article.
Guideline steering committee: Gordon $\mathrm{H}$ Guyatt (Chair), D. Norm Buckley, Jason W. Busse, David N. Juurlink

Guideline panel members: Jason W. Busse (Chair), Thomas Agoritsas, Elie A. Akl, Alonso Carrasco-Labra, Lynn Cooper, Chris Cull, Bruno R. da Costa, Joseph W. Frank, Gus Grant, Gordon H. Guyatt, Alfonso lorio, Navindra Persaud, Sol Stern, Peter Tugwell, Per Olav Vandvik

Clinical expert committee: D. Norm Buckley, Donna Buna, Gary Franklin, Chris Giorshev, Jeff Harris, Lydia Hatcher, Kurt Hegmann, Roman Jovey, David N. Juurlink, Priya Manjoo, Pat Morley-Forster, Dwight Moulin, Mark Sullivan

Patient advisory committee:* Bart Bennett, Lynn Cooper, Chris Cull, Ada Giudice-Tompson, Deborah Ironbow, Pamela Jessen, Mechelle Kane, Andrew Koster, Sue Mace, Tracy L. Mercer, Kyle Neilsen, Ian Tregunna, Jen Watson. *Three members did not provide written consent to be listed.

Evidence synthesis team: Samantha Craigie, Jason W. Busse, Li Wang, Rachel J. Couban, Vahid Ashoorion, Mahmood AmniLari, Yaping Chang, Kayli Culig, Kyle De Oliveria, Anna Goshua, Justin Ho, Patrick Hong, Alka Kaushal, Regina Li, Veena Manja, Curtis May, Yasir Rehman, John J. Riva, Stephanie Ross, Nicole Vogel, Raad Yameen, Madison Zhang

External review committee: Paul Glasziou (Chair), Pablo Alonso Coello, Miranda Langendam

Correspondence to: Jason W. Busse, bussejw@mcmaster.ca 